Claremont Colleges

Scholarship@ Claremont

All HMC Faculty Publications and Research

HMC Faculty Scholarship

6-1-2009

\title{
Generation of Mie Size Microdroplet Aerosols with Applications in Laser-Driven Fusion Experiments
}

Andrew P. Higginbotham '09

Harvey Mudd College

O. Semonin '06

Harvey Mudd College

S. Bruce '08

Harvey Mudd College

C. Chan '08

Harvey Mudd College

M. Maindi '07

Harvey Mudd College

See next page for additional authors

\section{Recommended Citation}

A.P. Higginbotham, O. Semonin, S. Bruce, C. Chan, M. Maindi, M. Maurer, W. Bang, I. Churina, J. Osterholz, I. Kim, A.C. Bernstein, T. Ditmire, T. D. Donnelly, "Generation of Mie size microdroplet aerosols with applications in laser-driven fusion experiments," Rev Sci. Instrum., 80, (2009).

This Article is brought to you for free and open access by the HMC Faculty Scholarship at Scholarship @ Claremont. It has been accepted for inclusion in All HMC Faculty Publications and Research by an authorized administrator of Scholarship @ Claremont. For more information, please contact scholarship@cuc.claremont.edu. 
Authors

Andrew P. Higginbotham '09, O. Semonin '06, S. Bruce '08, C. Chan '08, M. Maindi '07, Thomas D. Donnelly, M. Maurer, W. Bang, I. Churina, J. Osterholz, I. Kim, A. C. Bernstein, and T. Ditmire 


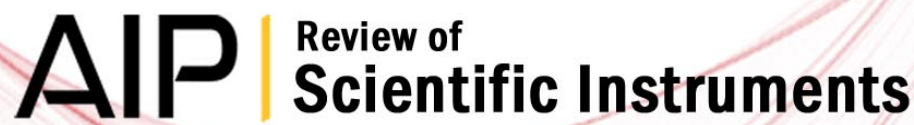

Generation of Mie size microdroplet aerosols with applications in laserdriven fusion experiments
A. P. Higginbotham, O. Semonin, S. Bruce, C. Chan, M. Maindi et al.

Citation: Rev. Sci. Instrum. 80, 063503 (2009); doi: 10.1063/1.3155302

View online: http://dx.doi.org/10.1063/1.3155302

View Table of Contents: http://rsi.aip.org/resource/1/RSINAK/v80/i6

Published by the AIP Publishing LLC.

\section{Additional information on Rev. Sci. Instrum.}

Journal Homepage: http://rsi.aip.org

Journal Information: http://rsi.aip.org/about/about_the_journal

Top downloads: http://rsi.aip.org/features/most_downloaded

Information for Authors: http://rsi.aip.org/authors

\section{ADVERTISEMENT}

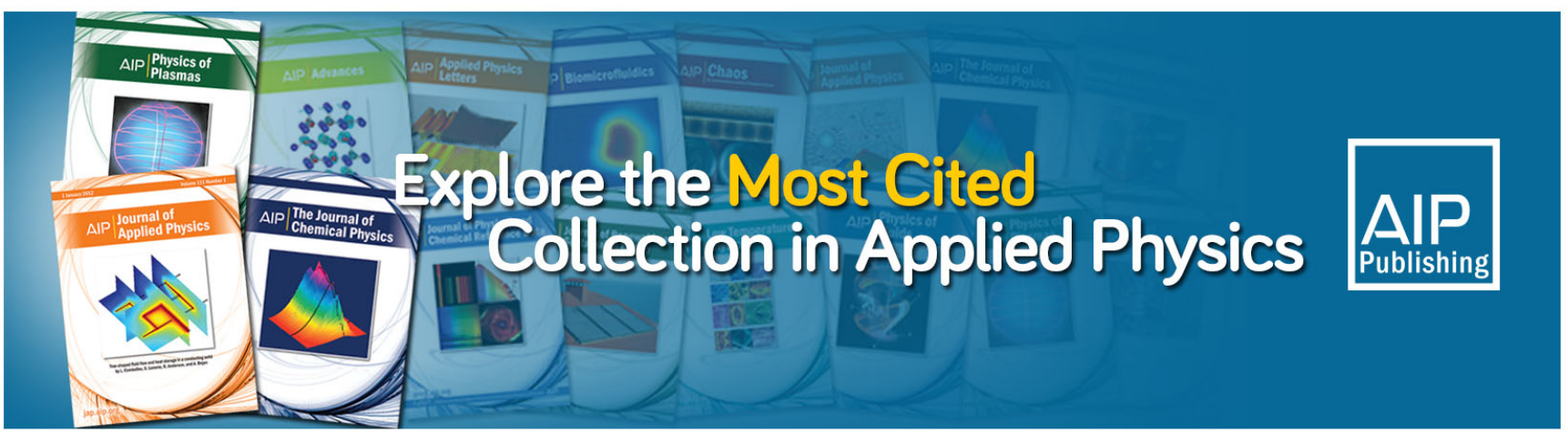




\title{
Generation of Mie size microdroplet aerosols with applications in laser-driven fusion experiments
}

\author{
A. P. Higginbotham, ${ }^{1}$ O. Semonin, ${ }^{1}$ S. Bruce,${ }^{1}$ C. Chan, ${ }^{1}$ M. Maindi, ${ }^{1}$ T. D. Donnelly, ${ }^{1}$ \\ M. Maurer, ${ }^{2}$ W. Bang, ${ }^{2}$ I. Churina, ${ }^{2}$ J. Osterholz, ${ }^{2}$ I. Kim, ${ }^{2}$ A. C. Bernstein, ${ }^{2}$ and \\ T. Ditmire ${ }^{2}$ \\ ${ }^{1}$ Department of Physics, Harvey Mudd College, Claremont, California 91711, USA \\ ${ }^{2}$ Department of Physics, Texas Center for High Intensity Laser Science, University of Texas, \\ Austin, Texas 78701, USA
}

(Received 15 December 2008; accepted 27 May 2009; published online 25 June 2009)

\begin{abstract}
We have developed a tunable source of Mie scale microdroplet aerosols that can be used for the generation of energetic ions. To demonstrate this potential, a terawatt $\mathrm{Ti}: \mathrm{Al}_{2} \mathrm{O}_{3}$ laser focused to $2 \times 10^{19} \mathrm{~W} / \mathrm{cm}^{2}$ was used to irradiate heavy water $\left(\mathrm{D}_{2} \mathrm{O}\right)$ aerosols composed of micron-scale droplets. Energetic deuterium ions, which were generated in the laser-droplet interaction, produced deuterium-deuterium fusion with approximately $2 \times 10^{3}$ fusion neutrons measured per joule of incident laser energy. (C) 2009 American Institute of Physics. [DOI: 10.1063/1.3155302]
\end{abstract}

\section{INTRODUCTION}

A source capable of producing energetic ions has application in medical imaging techniques such as positron emission tomography scans, ${ }^{1}$ plasma imaging, ${ }^{2,3}$ and the production of fusion. ${ }^{4-6}$ Laser-heated materials have often been used as a source for energetic ions, employing many target geometries and materials. Irradiation of thin films using short pulse lasers at intensities of $10^{19} \mathrm{~W} / \mathrm{cm}^{2}$ has resulted in the creation of ions with energies in the $5 \mathrm{MeV}$ range, ${ }^{7,8}$ however these films create significant debris when irradiated, which can be problematic. Atomic cluster targets have also been studied and shown to efficiently absorb laser energy (nearly 100\%), produce hot ions [1-100 keV (Ref. 9)], yield $10^{5}$ fusion neutrons per incident joule of laser energy, ${ }^{4,10}$ and they have the benefit of being nearly debris free. Ultimately, however, because the clusters are limited to small dimension $(\leq 100 \AA)$, they produce ions with a relatively low peak energy.

Motivated by the success of laser-cluster interactions in producing energetic ions and hoping to improve upon it, recent work has focused on laser-droplet interactions. The larger fluid droplets have the potential to produce more energetic ions $(\sim 1 \mathrm{MeV})$ than can the clusters $(\sim 1-100 \mathrm{keV})$. Karsch et al. ${ }^{5}$ and Ter-Avetisyan et al. ${ }^{6}$ have irradiated droplets of $15 \mu \mathrm{m}$ and $150 \mathrm{~nm}$ size to produce $\mathrm{MeV}$ ions and, in the latter case, demonstrated fusion. A gas jet was used to produce an aerosol containing the $150 \mathrm{~nm}$ droplets. ${ }^{11}$ Irradiation with high intensity $\left(10^{19} \mathrm{~W} / \mathrm{cm}^{2}\right)$ laser pulses leads to the production of $10^{4}$ fusion neutrons per incident Joule of laser energy. These are relatively high neutron yields and demonstrate the expected increase in reaction probability compared to the smaller cluster targets.

However, this work $^{5,6,11}$ straddles the Mie regime of the laser-matter interaction, where the target size is on the order of the wavelength. It has been well established ${ }^{12}$ that for Mie sized targets, a hot ion population is produced with energies of up to 1-2 MeV. Furthermore, studies of hard x-ray yield by irradiation of Mie size targets have shown that Mie effects can enhance hot electron number and temperature, ${ }^{13,14}$ indicating a more efficient coupling of laser energy into the target when the appropriate size is used. The increase in coupling efficiency is thought to be due to Mie-like resonances in the field surrounding the target and therefore results in a highly anisotropic generation of hot ions. ${ }^{12}$ Indeed, the previous work on the irradiation of microdroplets outside of the Mie regime has not shown the significant spatial anisotropies visible in the Mie regime. ${ }^{5,6,15-17}$ For an appropriately designed micron-scale target, the Mie field enhancements may provide a means of maximizing ion energies and therefore fusion yield. The current method for producing these targets relies on a specially designed gas jet nozzle so that it is difficult to tune the droplet size in order to harness the expected ion energy increase in the Mie regime. Due to the limitations of the gas jet approach, a more tunable source is needed.

To overcome this limitation, we have built a uniquely flexible device that uses ultrasonic atomization to produce a dense aerosol of microdroplet laser targets of varying size. ${ }^{18,19}$ We have used this device in a set of experiments which demonstrate that this technique is a viable option for producing energetic ions and deuterium-deuterium (D-D) fusion. While our fusion neutron yield $\left(2 \times 10^{3}\right.$ neutrons per joule of laser energy) does not improve on existing results from gas clusters and other aerosols, the flexibility of ultrasonic atomization promises the ability to continuously adjust the target size in order to experimentally map the role of Mie-like resonances in ion acceleration and ultimately improve the fusion process.

\section{AEROSOL GENERATION VIA ULTRASONIC ATOMIZATION}

The microdroplets are generated via ultrasonic atomization. A piezoelectric transducer is placed in the bottom of a 


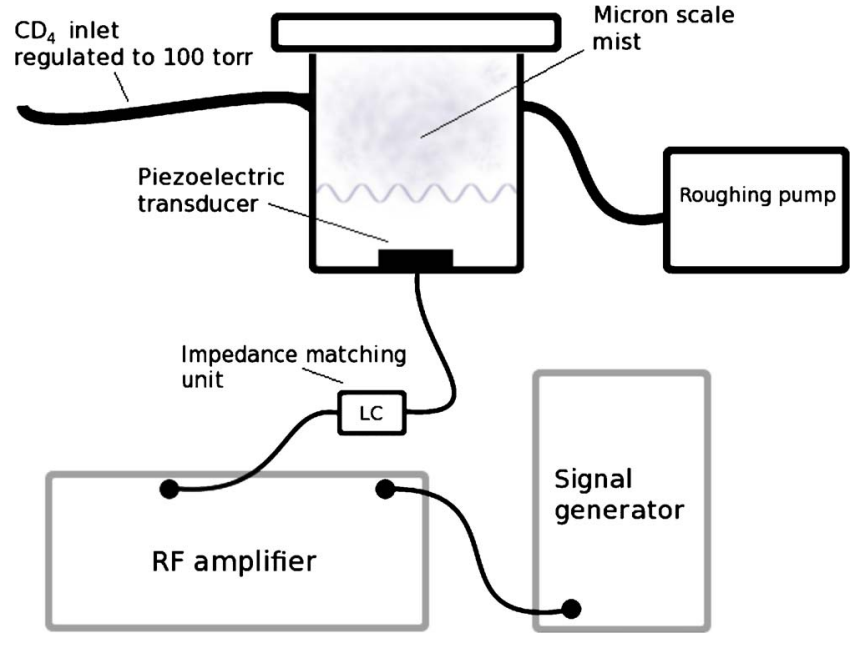

FIG. 1. (Color online) A high frequency piezoelectric transducer is placed at the base of a $\mathrm{D}_{2} \mathrm{O}$ bath. The piezoelectric transducer excites the fluid surface, causing the ejection of micron-scale droplets.

heavy water bath and is driven by a sinusoidal signal (Fig. 1). This creates a capillary wave pattern on the surface of the bath that is a function of the driving frequency and the fluid parameters. The dispersion relation for these waves is given by the Kelvin equation $\omega^{\prime 2}=\sigma k^{3} / \rho,{ }^{20}$ where $\omega^{\prime}$ is the capillary wave frequency and $k=2 \pi / \lambda$ is the wave number. The parameters $\sigma$ and $\rho$ are the surface tension and density of the fluid, respectively.

Heuristically, we should expect the diameter $d$ of the ejected droplets to be on the order of the wavelength of the capillary wave at the fluid surface so that $d=c \lambda$. The proportionality constant $c$ has been experimentally measured to be $c=0.34$ (Ref. 21) over a wide range of excitation frequencies, including verification in our regime. ${ }^{18,19}$

Using this assumption, combined with the fact that the frequency of the capillary waves generated on the surface of the fluid is generally related to the driving frequency $\omega$ by $\omega^{\prime}=\omega / 2,{ }^{22}$ we may write the ejected droplet radius as a function of excitation frequency as

$$
r=\pi c\left(\frac{\sigma}{\rho}\right)^{1 / 3}\left(\frac{2}{\omega}\right)^{2 / 3}
$$

By exciting the water bath with transducers of varying $\omega$, a droplet radius range of $0.2-10 \mu \mathrm{m}$ may be achieved.

By varying the driving frequency $(\omega)$ of the transducer, ultrasonic atomization promises the ability to create a wide range of droplet sizes. While the inherent tunability promises the ability to significantly explore Mie regime targets, the technique, for water, becomes fundamentally limited at excitation frequencies on the order of $30 \mathrm{MHz}$, which corresponds to a smallest possible droplet radius of $0.2 \mu \mathrm{m}$. The limitation of this technique can be seen by consideration of the $p$-wave (sound wave) attenuation length $\Lambda$ in water, which may be written in terms of the excitation frequency $\nu$ $\operatorname{as}^{20}$

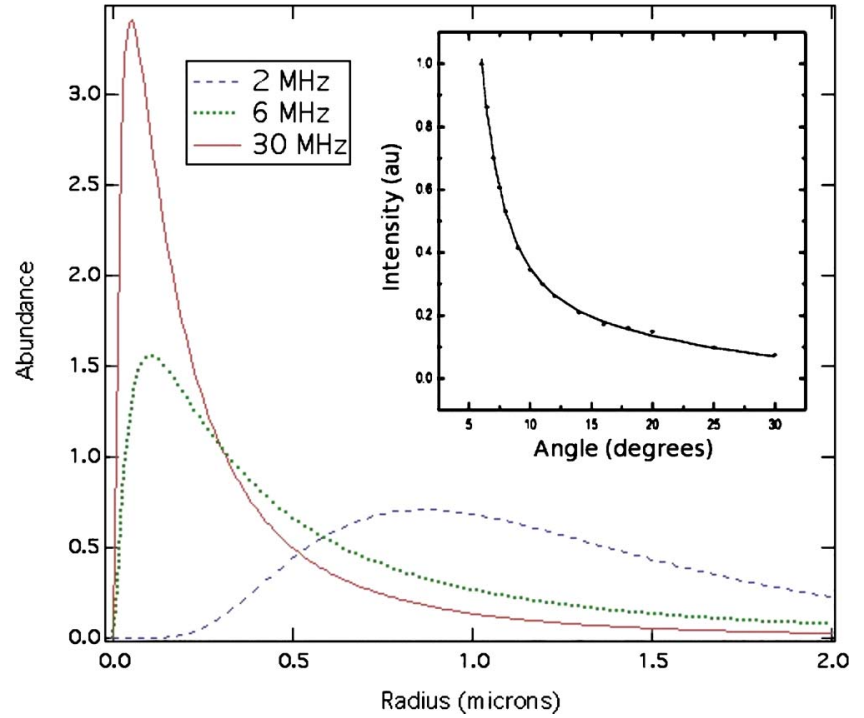

FIG. 2. (Color online) Sample particle size distributions. Using a measured angular scattering intensity profile, a droplet distribution is found. The 6 and $2 \mathrm{MHz}$ distributions were fit from Mie scattering experiments. The $30 \mathrm{MHz}$ distribution is generated numerically assuming distribution parameters similar to the $6 \mathrm{MHz}$. The 2 and $6 \mathrm{MHz}$ distributions are measured using Mie scattering as described in Refs. 18 and 19. A sample angular scattering distribution for a $2 \mathrm{MHz}$ oscillator is inset. The distributions indicate that by varying excitation frequency from 30 to $2 \mathrm{MHz}$, target radii from $0.2-1 \mu \mathrm{m}$ may be produced.

$$
\Lambda=\frac{3 c_{p}^{3} \rho}{4 \eta+3 \zeta} \frac{1}{\omega^{2}}=2.3 \times 10^{13} \mathrm{~m} \mathrm{~s}^{2} / \nu^{2}
$$

where $\rho$ is the density of water, $c_{p}$ is the speed of sound in water, and $\eta$ and $\zeta$ are the viscosity and second viscosity of water. This assumes the standard values $\rho=1000 \mathrm{~kg} / \mathrm{m}^{3}$, $c_{p}=1500 \mathrm{~m} / \mathrm{s}$, and $\zeta=2.4 \eta=2.4 \times 10^{-3} \mathrm{~Pa} \mathrm{~s}^{23}$ For a 30 $\mathrm{MHz}$ driving frequency, this implies an attenuation length of $\Lambda=2.5 \mathrm{~cm}$. At these length scales, the technique becomes impracticable due to input power requirements, setting a lower bound on the droplet size realizable through ultrasonic atomization. In principle, with excitation frequencies from $10 \mathrm{kHz}$ to $30 \mathrm{MHz}$, the creation of microdroplet targets is well suited for exploring the efficient coupling of laser energy into ions for targets ranging in radius from $0.2-10 \mu \mathrm{m}$. For the purposes of this particular experiment, we use piezoelectrics with driving frequencies of $6-12 \mathrm{MHz}$ to create droplets with mean radii of $0.5 \mu \mathrm{m}$.

\section{DROPLET SIZING TECHNIQUE}

The aerosol size distribution was measured using Mie scattering. Our methods and results are described more fully in Ref. 24. A $1 \mathrm{~W}$ argon ion laser operating at $488 \mathrm{~nm}$ is directed through the aerosol and an angular intensity profile is measured. The input signal is chopped and detected through a lock-in amplifier and then normalized to a reference detector to account for fluctuations in mist density and laser intensity.

The droplet size is assumed to be in a log-normal distribution. Thus the data are fit not for one size but for a mean size and variance. Example distributions, fit to angular scattering data, may be found in Fig. 2. The $6 \mathrm{MHz}$ distribution 


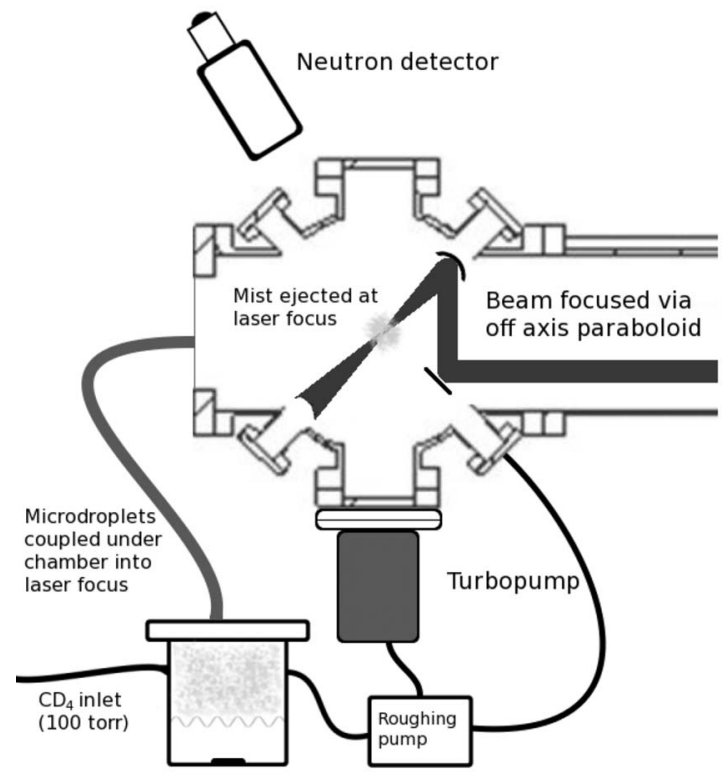

FIG. 3. Diagram of experimental apparatus. The neutron detector, placed $112.5 \mathrm{~cm}$ from the laser focus, measures neutrons generated when the laser pulse heats the microdroplets and initiates D-D fusion.

was generated by a piezoelectric driven at $6.6 \mathrm{MHz}$, which was the one used for fusion studies. For comparison, the measured distribution from a $2 \mathrm{MHz}$ oscillator, and a simulated distribution for a $30 \mathrm{MHz}$ oscillator are also presented. These distributions span the range of Mie size targets for an $800 \mathrm{~nm}$ laser. While we were not able to obtain oscillators at frequencies of greater than $12 \mathrm{MHz}$, they may be constructed at frequencies of up to $30 \mathrm{MHz}$.

\section{FUSION EXPERIMENT}

To demonstrate the utility of our device as a means of creating energetic ions, we irradiate our microdroplet heavy water aerosol with a high-intensity laser to initiate D-D fusion. The target aerosol is generated in a vacuum sealed chamber at 100 torr (Fig. 1). The chamber has a high frequency piezoelectric oscillator mounted in the bottom, is filled with a few centimeters of $\mathrm{D}_{2} \mathrm{O}$, and generates droplets via ultrasonic atomization. The pressure in the droplet chamber is actively controlled by a vacuum regulator that injects $\mathrm{CD}_{4}$ gas as necessary to maintain the operating pressure. $\mathrm{CD}_{4}$ is used both as a carrier gas and to provide additional fusion targets. No fusion neutrons are generated when the $\mathrm{CD}_{4}$ gas is irradiated without $\mathrm{D}_{2} \mathrm{O}$ droplets present, indicating that under these conditions the $\mathrm{CD}_{4}$ does not cluster and act as a source of energetic ions.

The droplet chamber is coupled to the target chamber, which is held at an operating pressure of $5 \times 10^{-5}$ torr (Fig. 3 ). The two chambers are connected via a vacuum sealed solenoid valve. The valve was opened for $20 \mathrm{~ms}$ to allow the aerosol to flow from the relative high pressure of the mist chamber to the lower pressure of the vacuum chamber. This valve was opened $80 \mathrm{~ms}$ before the laser pulse arrived, allowing this mist to travel the span of $1.2 \mathrm{~m}$ to reach the focal point in the targeting chamber. In selecting a solenoid valve, it is important to choose a high flow rate system $\left(\mathrm{C}_{\mathrm{v}} \sim 0.2\right)$ to avoid droplet coalescence. At lower flow rates, it was found that moisture was deposited in the valve and eventually froze. Due to the long opening time of the solenoid valve, the system has a maximum repetition rate of about one shot every minute. To improve this rate, a differential pumping system might be employed to quickly remove excess fluid and increase the overall repetition rate of the system. ${ }^{25}$

A laser pulse is focused on the aerosol to produce fusion events. We use the 10 TW Texas high-intensity optical research (THOR) $\mathrm{Ti}: \mathrm{Al}_{2} \mathrm{O}_{3}$ laser, which delivers $0.6 \mathrm{~J}, 35 \mathrm{fs}$ pulses. The laser is focused using an $f / 2.7$ off-axis parabolic mirror to achieve an intensity of approximately 2 $\times 10^{19} \mathrm{~W} / \mathrm{cm}^{2}$ at focus. ${ }^{26}$ Similar experimental geometries have previously yielded ions, which are accelerated from the plasma $^{12}$ in the MeV range. ${ }^{15-17}$

The $\mathrm{MeV}$ ions that are generated as described above are accelerated outwards and collide with fluid deuterium targets. The familiar deuterium fusion reactions

$$
\begin{aligned}
& \mathrm{D}+\mathrm{D} \rightarrow \mathrm{He}^{3}+\mathrm{n}, \\
& \mathrm{D}+\mathrm{D} \rightarrow \mathrm{T}+\mathrm{p}
\end{aligned}
$$

can occur. Isospin invariance implies that the first reaction must occur $50 \%$ of the time, therefore by measuring neutrons we can accurately calculate the total number of fusion reactions that occurred through both channels.

A neutron detector was placed $112.5 \mathrm{~cm}$ from the target chamber and held at a bias voltage of $-1800 \mathrm{~V}$. The detector consists of a circular plastic scintillator head with a diameter of $12.7 \mathrm{~cm}$, a thickness of $9 \mathrm{~cm}$, and a Photonis XP4512 photomultiplier tube base. The detector is shielded with approximately $10 \mathrm{~cm}$ of lead to attenuate the sizable $\mathrm{x}$-ray pulse created when the droplets are irradiated. ${ }^{13}$

\section{RESULTS}

A sample signal from the neutron detector is given in Fig. 4. The first, larger dip is the hard x-ray pulse created from the rapid acceleration of electrons during the droplet ionization process. The second dip, near $120 \mathrm{~ns}$, represents the arrival of a single neutron. The expected neutron time of arrival may be calculated kinematically from the $2.45 \mathrm{MeV}$ neutron energy and the distance between the detectors and the reaction chamber.

For the six laser shots we observed neutrons, the average signal to noise ratio was 14.0. Unlike the signal shown in Fig. 4, the signal displayed in Fig. 5 exhibited significant ringing after the arrival of the x-ray pulse. In order to determine the background signal in these cases, a discrete Fourier transform of the data was taken and the frequency components that correspond to the ringing were removed. This allowed for a better estimate of the background noise, as shown in Fig. 5.

Neutrons were detected on approximately $25 \%$ of the laser shots. There were no clear multiple neutron events, however it is difficult to conclude with certainty that no double neutron events were observed because of the sparse statistics and noise from hard X-rays. We assume in our analysis that only single neutrons were detected, and thus calculate a lower bound on the neutron yield of our device. 


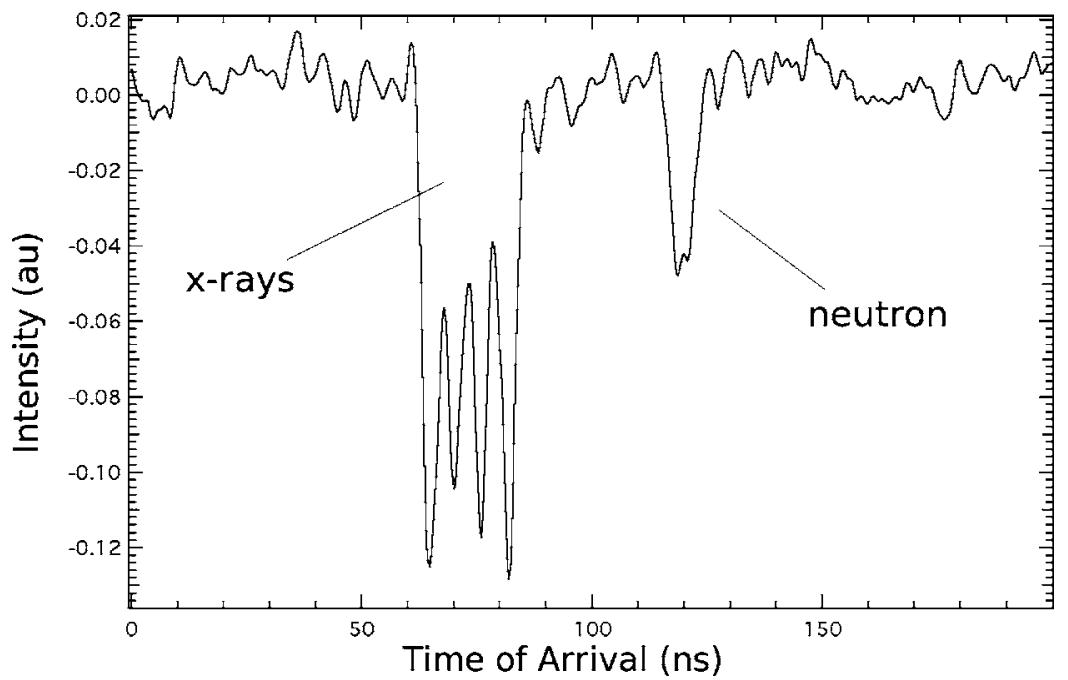

FIG. 4. A sample neutron signal. The neutron arrives close to the expected time of $50 \mathrm{~ns}$ after the x-ray pulse. The time of arrival is measured as the difference between the leading edge of each pulse to take into account variations in detector response due to saturation. A natural spread of approximately $10 \mathrm{~ns}$ may be observed due to neutron scattering, which is typical of D-D laser-driven fusion studies (Ref. 27).

If the neutron distribution is isotropic, then the probability of detecting a neutron is given exactly by a binomial distribution. However, because of the relatively sparse statistics, in this case the Poisson distribution

$$
P_{k}=\frac{\lambda^{k} e^{-\lambda}}{k !}
$$

gives an excellent approximation of the probability of detecting $k$ neutrons. It is fairly straightforward to show that the constant $\lambda$ is given by $\lambda=S N /(4 \pi)$, where $S$ is the solid angle subtended by the detector measured in steradians and $N$ is the total number of neutrons. Since only single neutrons were detected, we may use the fact that $P_{1} \sim 0.25$ to estimate $N \sim 450$.

We may now calculate the probability of detecting two neutrons to be $P_{2}=0.04$. The probability of observing only single neutrons is then $\left(1-P_{2}\right)^{25} \sim 35 \%$. This suggests that our assumption that no double neutron events were recorded gives a plausible lower bound of the neutron yield.

Additionally, it should be noted that we have thus far assumed $100 \%$ detector efficiency. Taking into account the mean free path of neutrons in the detector and neutron attenuation due to the lead shielding, ${ }^{28,29}$ a safe estimate of the detector efficiency is $40 \%$, implying a corrected neutron yield on the order of 1100 neutrons per shot, or 2200 neutrons per incident joule of laser energy. This figure is comparable to the neutron yields found in previous work with similarly sized targets. ${ }^{5,6}$ We consider the quoted neutron yield of $2 \times 10^{3}$ neutrons per incident joule of laser energy to be an appropriately conservative estimate of the neutron yields available from this device, but more work is needed to thoroughly characterize the fusion, as well as explore its dependence on droplet size.

\section{SUMMARY}

We use ultrasonic atomization to produce a tunable, Mie size microdroplet aerosol. This aerosol, composed of $0.5 \mu \mathrm{m}$ heavy water droplets, is irradiated with a short-pulse (35 fs) laser at intensities of $10^{19} \mathrm{~W} / \mathrm{cm}^{2}$ to produce energetic ions and D-D fusion. Fusion neutrons are observed on $25 \%$ of laser shots, implying a yield of approximately

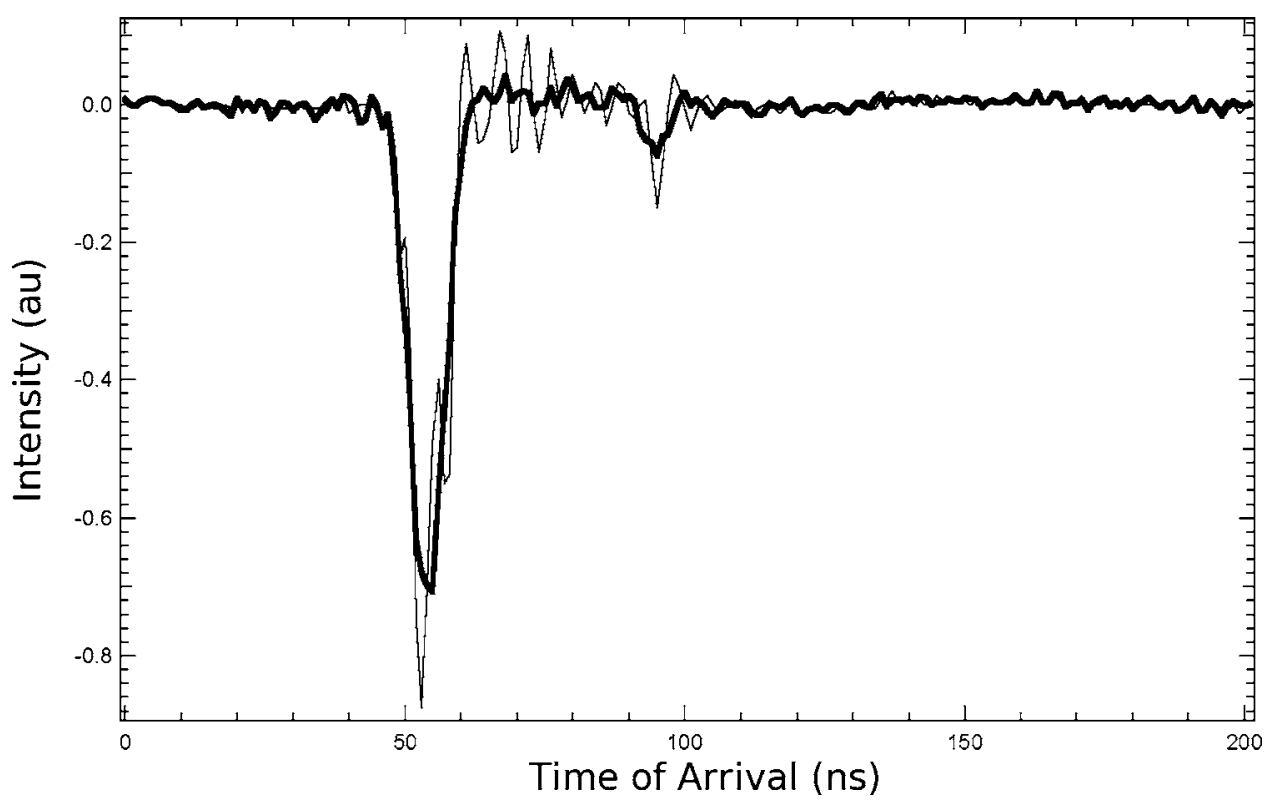

FIG. 5. Using a FFT, frequency components corresponding to detector ringing were removed to give a more accurate estimate of the background noise near the neutron signal. The lighter signal is the original, with the transformed signal overlaid and bolded. The neutron arrives almost exactly at the expected time. 
$2 \times 10^{3}$ fusion neutrons per incident joule of laser energy, assuming an isotropic neutron distribution. The ultrasonic atomization technique promises the ability to generate even smaller deuterium droplet targets that can be used to exploit Mie enhancements of the field, and presumably increase fusion yield.

\section{ACKNOWLEDGMENTS}

We thank A. J. Bernoff for stimulating discussion and helpful insights. We also wish to acknowledge Annie Atiyeh and Mike Wheeler for their valuable assistance. This work was supported by the National Science Foundation under Grant Nos. PHY-0456898, PHY-0757989, and PHY-0456870 and the National Nuclear Security Administration under Cooperative Agreement No. DE-FC52-03NA00156. Acknowledgment is made to the Donors of the Petroleum Research Fund administered by the American Chemical Society for partial support of this research.

${ }^{1}$ M. Yamagiwa and J. Koga, J. Phys. D 32, 2526 (1999).

${ }^{2}$ M. Borghesi, S. Bulanov, D. H. Campbell, R. J. Clarke, T. Zh. Esirkepov, M. Galimberti, L. A. Gizzi, A. J. MacKinnon, N. M. Naumova, F. Pegoraro, H. Ruhl, A. Schiavi, and O. Willi, Phys. Rev. Lett. 88, 135002 (2002).

${ }^{3}$ M. I. K. Santala, M. Zepf, F. N. Beg, E. L. Clark, A. E. Dangor, K. Krushelnick, M. Tatarakis, I. Watts, K. W. D. Ledingham, T. McCanny, I. Spencer, A. C. Machacek, R. Allott, R. J. Clarke, and P. A. Norreys, Appl. Phys. Lett. 78, 19 (2001).

${ }^{4}$ T. Ditmire, J. Zweiback, V. P. Yanovsky, T. E. Cowan, G. Hays, and K. B. Wharton, Nature (London) 398, 489 (1999).

${ }^{5}$ S. Karsch, S. Düsterer, H. Schwoerer, F. Ewald, D. Habs, M. Hegelich, G. Pretzler, A. Pukhov, K. Witte, and R. Sauerbrey, Phys. Rev. Lett. 91, 015001 (2003).

${ }^{6}$ S. Ter-Avetisyan, M. Schnürer, D. Hilscher, U. Jahnke, S. Busch, P. V. Nickles, and W. Sandner, Phys. Plasmas 12, 012702 (2005).

${ }^{7}$ M. Hegelich, S. Karsch, G. Pretzler, D. Habs, K. Witte, W. Guenther, M. Allen, A. Blazevic, J. Fuchs, J. C. Gauthier, M. Geissel, P. Audebert, T. Cowan, and M. Roth, Phys. Rev. Lett. 89, 085002 (2002).
${ }^{8}$ S. J. Gitomer, R. D. Jones, F. Begay, A. W. Ehler, J. F. Kephard, and R. Kristal, Phys. Fluids 29, 2679 (1986).

${ }^{9}$ T. Ditmire, J. W. G. Tisch, E. Springate, M. B. Mason, N. Hay, R. A. Smith, J. Marangos, and M. H. R. Hutchinson, Nature (London) 386, 54 (1997).

${ }^{10}$ I. Last and J. Jortner, Phys. Rev. Lett. 87, 033401 (2001).

${ }^{11}$ S. Ter-Avetisyan, M. Schnürer, H. Stiel, and P. V. Nickles, J. Phys. D 36, 2421 (2003)

${ }^{12}$ D. R. Symes, A. J. Comley, and R. A. Smith, Phys. Rev. Lett. 93, 145004 (2004).

${ }^{13}$ T. D. Donnelly, M. Rust, I. Weiner, M. Allen, R. A. Smith, C. A. Steinke, S. Wilks, J. Zweiback, T. E. Cowan, and T. Ditmire, J. Phys. B 34, L313 (2001).

${ }^{14}$ H. A. Sumeruk, S. Kneip, D. R. Symes, I. V. Churina, A. V. Belolipetski, T. D. Donnelly, and T. Ditmire, Phys. Rev. Lett. 98, 045001 (2007).

${ }^{15}$ M. Schnürer, S. Ter-Avetisyan, S. Busch, M. P. Kalachnikov, E. Risse, W. Sandner, and P. V. Nickles, Appl. Phys. B: Lasers Opt. 78, 895 (2004).

${ }^{16}$ S. Ter-Avetisyan, M. Schnürer, P. V. Nickles, M. Kalashnikov, E. Risse, T. Sokollik, W. Sandner, A. Andreev, and V. Tikhonchuk, Phys. Rev. Lett. 96, 145006 (2006)

${ }^{17}$ S. Busch, M. Schnürer, M. Kalashnikov, H. Schönnagel, H. Stiel, P. V. Nickles, W. Sandner, S. Ter-Avetisyan, V. Karpov, and U. Vogt, Appl. Phys. Lett. 82, 3354 (2003).

${ }^{18}$ T. D. Donnelly, J. Hogan, A. Mugler, M. Schubmehl, N. Schommer, A. J. Bernoff, S. Dasnurkar, and T. Ditmire, Rev. Sci. Instrum. 76, 113301 (2005).

${ }^{19}$ T. D. Donnelly, J. Hogan, A. Mugler, N. Schommer, M. Schubmehl, A. J. Bernoff, and B. Forrest, Phys. Fluids 16, 2843 (2004).

${ }^{20}$ L. D. Landau and E. M. Lifshitz, Fluid Mechanics (Pergamon, London, England, 1959).

${ }^{21}$ R. J. Lang, J. Acoust. Soc. Am. 34, 6 (1962).

${ }^{22}$ T. B. Benjamin and F. Ursell, Proc. R. Soc. London, Ser. A 225, 505 (1954).

${ }^{23}$ L. N. Liebermann, Phys. Rev. 75, 1415 (1949).

${ }^{24}$ I. Weiner, M. Rust, and T. D. Donnelly, Am. J. Phys. 69, 129 (2001).

${ }^{25}$ S. Düsterer, H. Schwoerer, W. Ziegler, C. Ziener, and R. Sauerbrey, Appl. Phys. B: Lasers Opt. 73, 693 (2001).

${ }^{26}$ W. Grigsby, "Experimental Studies of High Energy Density Silicon Using Ultra-Fast Lasers," Ph.D. thesis, University of Texas at Austin, 2007.

${ }^{27}$ R. Hartke, D. R. Symes, F. Buersgens, L. Ruggles, J. L. Porter, and T. Ditmire, Nucl. Instrum. Methods Phys. Res. A 540, 464 (2005).

${ }^{28}$ M. Walt and H. H. Barschall, Phys. Rev. 93, 1062 (1954).

${ }^{29}$ W. J. Rhein, Phys. Rev. 98, 1300 (1955). 